\title{
Using Lean Management Principles to Improve Patient Satisfaction and Reduce Wait Times at UNM GI/Endoscopy
}

\author{
Aim of project \\ To use Lean management principles to increase \\ overall patient satisfaction by improving cycle time \\ for procedure room turnover, improving overall cycle \\ time, and developing methods to anticipate work \\ ahead of time.

\section{Background} \\ Lean management principles have been used \\ effectively in manufacturing companies for decades, \\ particularly in Japan. The Institute for Healthcare \\ Improvement believes that Lean principles can be - \\ indeed, already are being — successfully applied to \\ the delivery of health care.
}

Lean thinking begins with driving out waste so that all work adds value and serves the customer's needs. Identifying value-added and non-value-added steps in every process is the beginning of the journey toward lean operations.

In the UNM endoscopy unit we noticed that patients had longer wait, discharge and recovery times than the national average. Additionally, patient satisfaction was below average. To address this, we decided to use the lean process to identify areas for improvement.

The areas we identified are include:

1. The front desk was found to be a bottleneck that prevents timely procedures.

2. Recovery room turnover is 50 minutes, which is $\mathbf{3 0}$ minutes longer than reported best practices.

3. Triage was found to halt when there were no empty beds required by patients needing admission.

4. Nurses and technicians were not available during lunch, which caused significant delays in getting started on afternoon procedures.

\section{Planned intervention}

Using PDSA (Plan, Do, Study, Act) methodology to assess and develop areas of improvement as shown in figure 1. 
Figure 1: PDSA Diagram with planned intervention.

\section{THE Plan Do Study Act CYCLE}

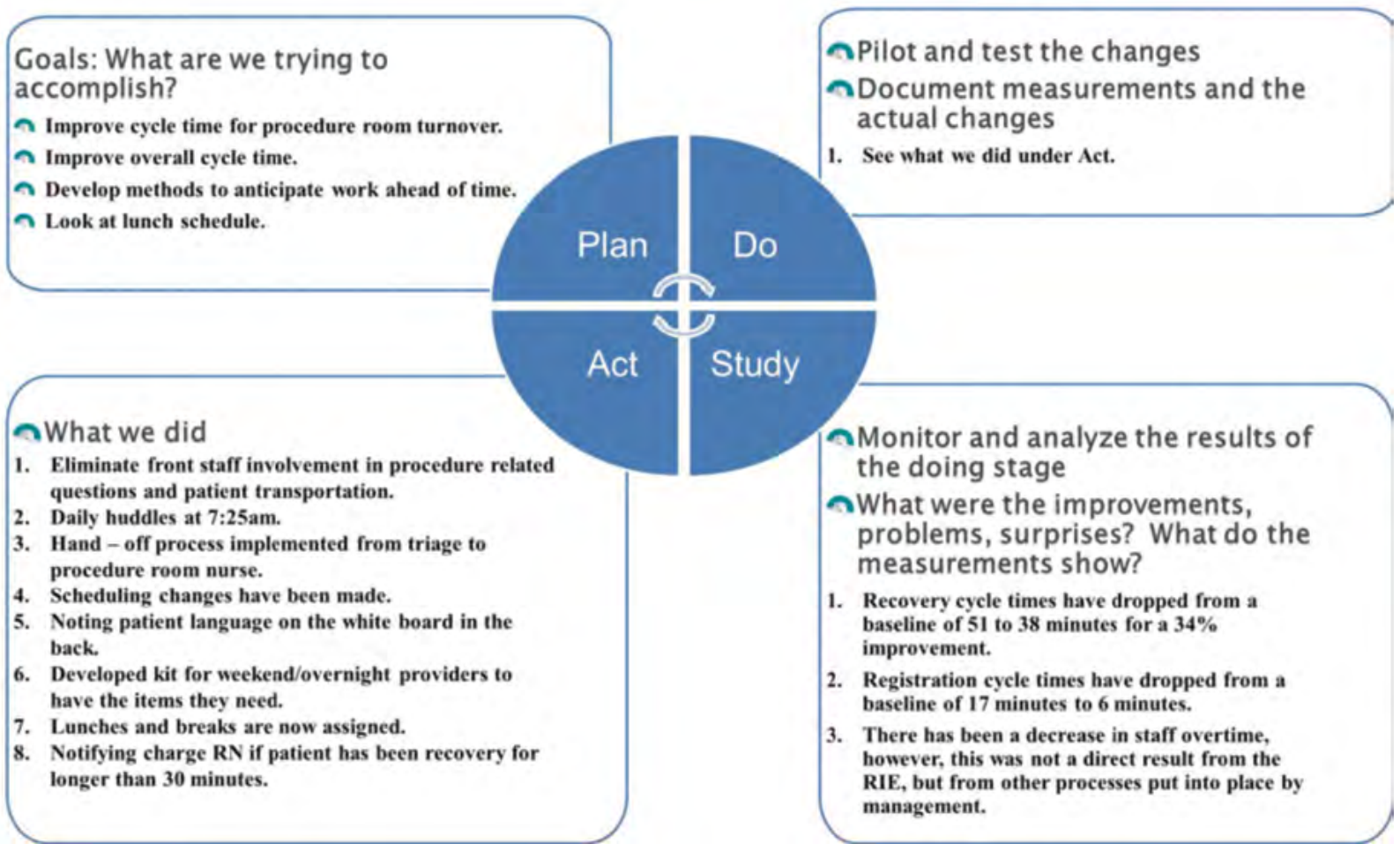

\section{Results}

Using Lean methodology and implementing the Plan, Do, Act, Study (PDSA) Cycle have significantly reduced procedure cycle time and improved patient satisfaction.

Staff involvement and sense of ownership of the change have been reported.

Waste elimination and time saving have directly improved productivity and reduced costs. 
Figure 2: Continuous process improvement; with recovery time and registration time improvement at different time points.

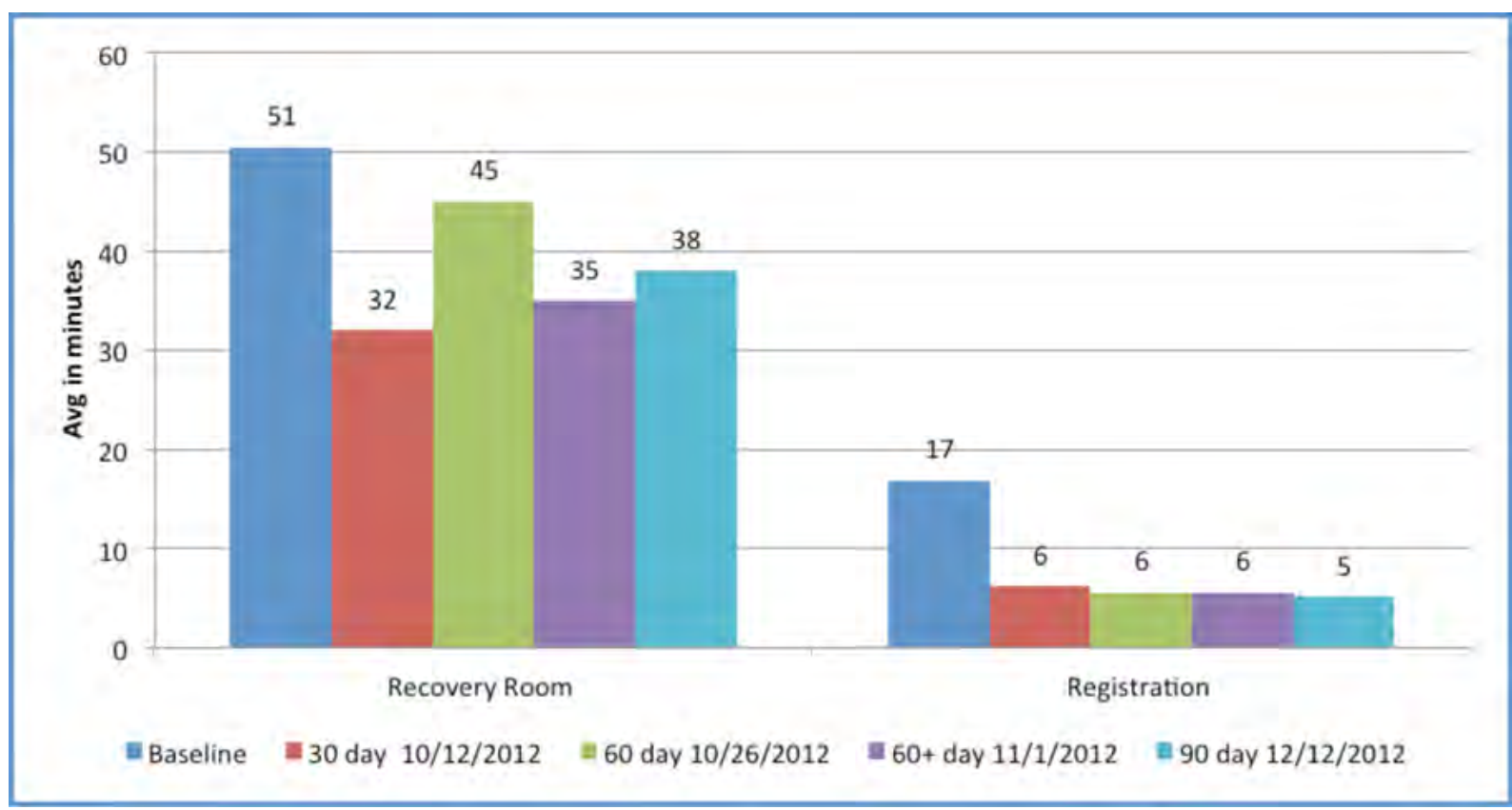

Figure 3: Patient overall satisfaction using PRESS GANEY hospital wide survey system.

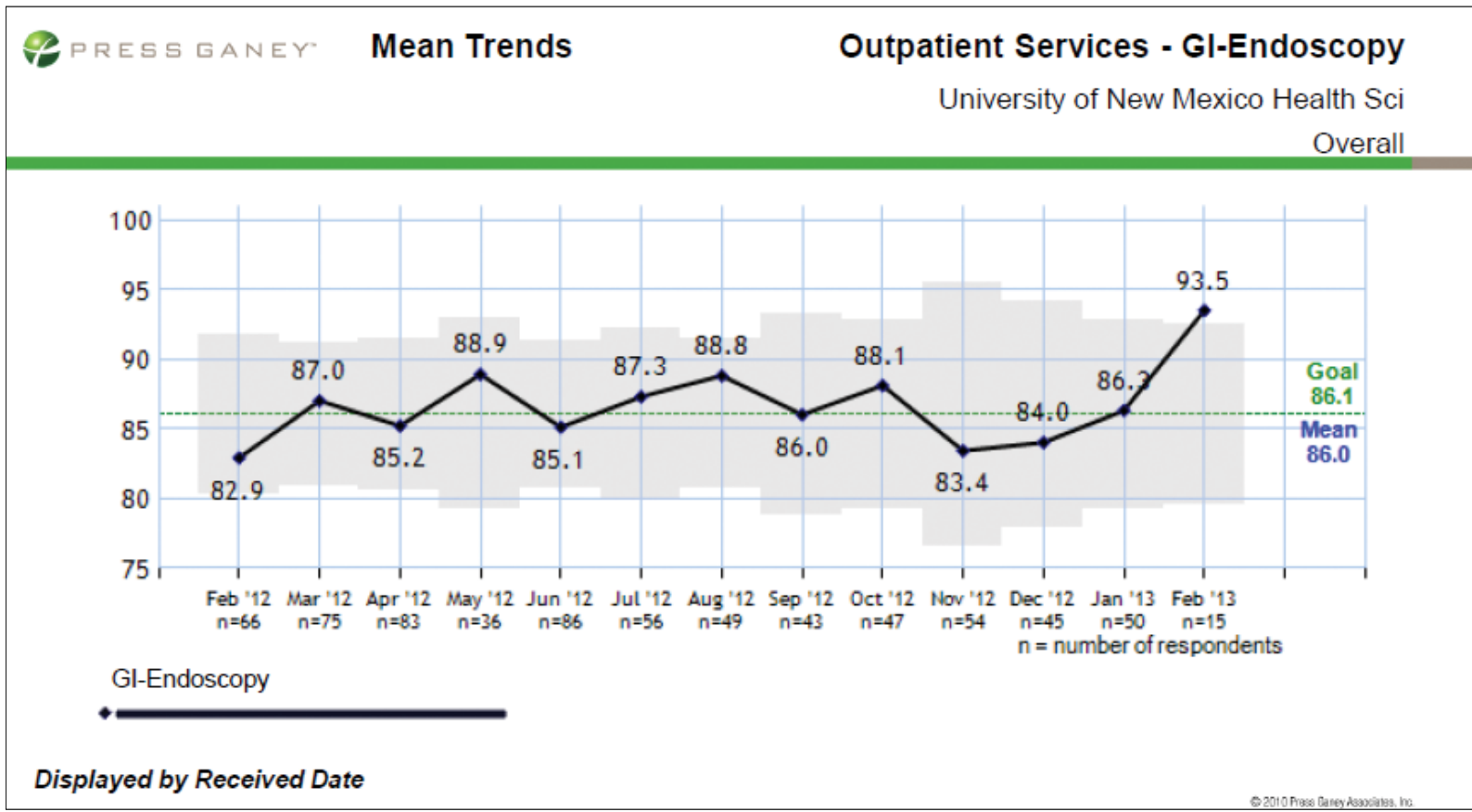

\section{Conclusions}

Health care delivery systems are striving to provide quality care at low cost. Our study demonstrates that Lean management principles and the PDSA process improvement can significantly improve health care delivery and provide costs saving as it has in other industries.

MOUSTAFA YOUSSEF, MD, MARTIN KISTIN, MD, GULSHAN PARASHAR, MD AND THOMAS MA, MD Division of Gastroenterology and Hepatology, Department of Internal Medicine, University of New Mexico 